\title{
But can it be Art? \\ Kapa Haka as a contemporary indigenous performance practice
}

\section{Mihi}

Kei te Hunga Kāinga, Te Ati Awa, Toa Rangatira, koutou o te Ngahuru o ngā iwi o tēneki takiwā, tēnā koutou katoa. Kei te Komiti Whakahaere, nō koutou te whakaaro rangatira kia tū ai tēneki hui ngāku mihi nui. Te Minenga e pae nei me ō koutou hiahia ki te whakawhiti whakaaro, korero hoki nau mai, haere mai, whakaoko mai! Mōku ake e harikoa ana ki Te Kaupapa kua whiriwhirihia mō tēneki hui kia whai wā anō ai ki te wānanga I tāku e ngākau nui ai, ko te Kapa Haka. Kia kaua hoki e wareware I ahau ko Taku Hoa, ko Sharon. Nāna ahau I akiaki kia puta ngā korero kua roa e noho nei ki ahau. Kia tukuna tā tātou hui e rere tonu ana. Pai mārire! Hau!

\section{Sharon speaks}

Kia ora Te Rita. I want to begin by thanking the Kōwhiti organisers - especially Jenny Stevenson, Linda Ashley and Peter Cleave - who have so generously brought us to this particular here and now. Te Rita introduced me to Māori performance and culture - especially Kapa Haka - about fifteen years ago, and I remain deeply grateful to her for, amongst so many gifts, in effect, opening up a whole new field of research for me as a Performance Studies scholar and for keeping a watchful, critical eye on the results of my ramblings.

This talk represents the latest stage in our ongoing conversation. As with our previously performed public Sharon Mazer is Associate Professor of Theatre and Performance Studies at AUT. Te Rita Papesch (Waikato/Maniapoto, Ngati Porou) is currently completing her $\mathrm{PhD}$ on 'The Role of Kapa Haka in Creating a Modern Māori Identity'. 
dialogues such as 'Crossing the Cultural Divide' in 2001and 'Stages of Pōwhiri' in 2008, we're staking positions that are to some degree more contrary than we might hold in private (see Papesch and Mazer 2001 \& 2010). We do this for the sake of argument, to have a bit of a play with thinking out loud in ways that you may, or may not, find acceptable, and as such perhaps to spark controversy, because we believe that conscious contentiousness can be cheerful and also genuinely productive of new ideas about the relationship between culture and performance.

We received the kaupapa of this wonderful event as a challenge. Te Rita is a prominent Kapa Haka performer, judge and commentator whose $\mathrm{PhD}$ makes serious claims for the role played by Kapa Haka in creating a modern Māori identity. I am a Theatre and Performance Studies scholar, in practice really a Performance Ethnographer, better known for my writing about professional wrestling, perhaps, than for my recent publications exploring diverse aspects of Māori performance. We don't do contemporary dance, indigenous or otherwise, we thought. (Well, I've done a bit on Atamira Dance Collective, but even there my focus was on the way they weave haka and waitata into the dominant European art form with which they are identified.) Our reflexive response was that we couldn't do this, because Kapa Haka is a traditional cultural performance practice, as such still rooted in ritual and very much not 'contemporary' or 'dance' per se. In fact, we reflexively - saw Kapa Haka on the opposite end of a binary from 'contemporary indigenous dance', whatever that is, and further, we were troubled by the whole idea of 'contemporary indigenous dance' which we - and we admit to being shortsighted in this - saw as a contradiction in terms.

And then . . . well, then we did a bit of temporal math, remembering that Kapa Haka is only forty years old in its current form, although its roots run deep. In fact, Kapa Haka is actually such a recent development - modern, if not contemporary - that we have spent much of our academic time 
struggling with its identification as 'traditional' and coming to argue in the affirmative for its status as an 'invented tradition'. As such, Kapa Haka can certainly be seen as a genre of contemporary indigenous performance practice, aligned with other such practices worldwide and both standing on its own and at the same time contributing to a large number of contemporary dance performances and aesthetics. What took us so long? Why could we not see Kapa Haka on the same terms as we might the latest work by Atamira?

And so we ask: What happens when we speak of 'indigenous' and 'contemporary' in the same sentence, and how might the 'traditional' performance that is Kapa Haka also be called 'Art' - not just when it's been woven into a piece of contemporary dance theatre, but standing on its own, on the Te Matatini stage and beyond?

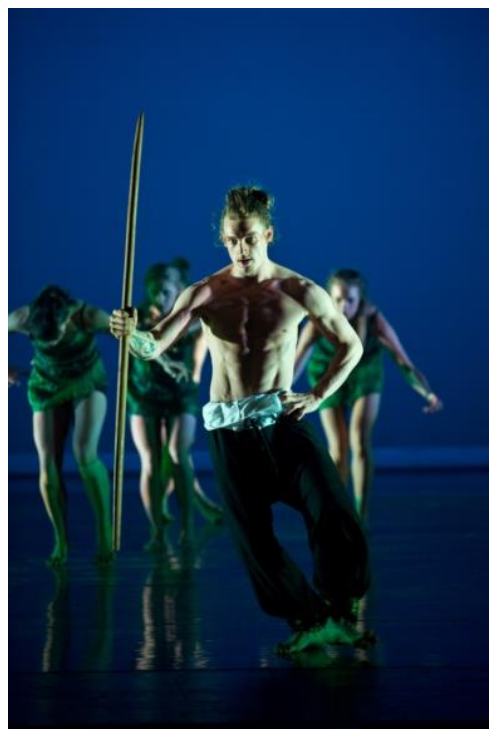

Photo: Stephen A'Court - Rangimarie by Merenia Gray Pictured: Emily Adams, Alice Macann, Olivia McGregor and Luke Hanna 
Kapa Haka in the $21^{\text {st }}$ century can be seen as a performative tukutuku panel: a distinctive genre of Māori song and dance, interwoven from ritual, sport, theatre, and pop culture to produce an evolving sense of what it is to be Māori in post-colonial Aotearoa New Zealand. Bound in te reo and tikanga, yet set into a European frame, speaking to a predominantly Māori audience and simultaneously broadcast to the world, Kapa Haka is vitally poised between the pre- and the post-colonial, between the 'native' and the 'European', between the 'traditional' and the 'contemporary', and between the 'indigenous' and 'art' - all artificial binaries, categorical imperatives that are only as meaningful as we - and those around us - make them.

Allow me to take a shot at what most of you will most likely see as an easy target: Ihi FrENZy, produced by the Royal New Zealand Ballet with prominent Kapa Haka troupe, Te Mātārae I O Rehu. More than ten years on from its performances in 2001, I remain fascinated and perplexed by the way the producers' biculturalist ambitions were played out on stage. It was a performance of two distinct halves: the first part Kapa Haka, choreographed by Wetini Mitai-Ngatai (Ihi), and the second Ballet, choreographed by Mark Baldwin (FrENZy). The description of the first part, which still can be seen on the NZ Ballet's website, could be used to promote a tourism venture in Rotorua: 'Ihi (power), shows traditional Maori performance at its best - if you thought the All Blacks' haka was fierce, think again!' For its part, the Ballet staked itself on going mod, dancing to the music of Split Enz - 'as Kiwi as it comes!' The two groups crossed paths in the middle, and danced together only for the curtain call, when the entire company took up the haka - finally.

(Bear with me, please. I know this is a minefield, that there were politics behind the scenes, a full catalogue of issues and conflicting accounts of how the project came together and what it meant for the participants. I am, however, wanting to be relatively superficial here - to look once again at what I saw 
as the well-meaning, highly contradictory, danced performance of cultural assumptions in a relatively contemporary frame. I am also taking advantage of the rather ambivalent status of this production to make points that you will almost certainly find objectionable when I turn to Atamira Dance Collective, whose work is ever so admirable, but not beyond critical analysis, I hope.)

First, I want to look at the second half of the performance - the FrENZy performed by the New Zealand Ballet - in order to make some of the most obvious of obvious points. Ballet is an old practice. A traditional European cultural performance practice, one might say. Centuries older, tracing itself to the courts of Europe and its high culture stages and imported to New Zealand as one of the key signs of civilisation, the Ballet is, perhaps, even more codified than Kapa Haka. In FrENZy, we see the Ballet straining at the edges of its own formalism, and its European-ness. The music is just dated enough thirty years - for most of us in the audience to receive it as a part of our collective history. In choosing the quintessentially Kiwi pop music of Split Enz, the Ballet performs itself as almost contemporary but not quite, and claims the band's iconicity for itself and, by proxy, for the audience.

In Ihi FrENZy the Ballet does not acquire its not-quite contemporary, but not-quite-not-contemporary, and no longer really European but rather 'as Kiwi as it comes!' aura in isolation, of course. Rather, our view of the Ballet is framed by the lens created by the Kapa Haka performance both before and after.

It's a very deliberate set-up, especially in the construction of the movement from Part I - the Kapa Haka - to Part II - the Ballet. In the educational video, (Williams 2003), Wetini MitaiNgatai says: 'I wanted to join the old world New Zealand to the new world New Zealand' in marking the transition to the Ballet from the Kapa Haka. Passing along the feather - the taonga is an almost ritual act, an almost narrative moment, miming the welcoming of the European to the stage that has been just 
been occupied by - and now, except for that feather, is emptied of - the Kapa Haka. That is to say, in the most literal way possible, given the confines of the stage, the chronology of the performance reproduces the chronology, and the dominant narrative, of New Zealand (bi)cultural history. In the first act, we see the natives, 'the old world New Zealand', doing their song and dance, and then - and oh how graciously, lightly, gently as a feather after the ferocity of the haka - in the second, the natives give way to the Europeans, who are the 'new world New Zealand.' All that remains of the native (and nature), in this vision, is the feather which, as it is picked up and worn in the ballerina's hair, has been transformed from ritual object to adornment, not quite fitting the Ballet, but not in the way either, carried passively along . . . pretty that.

And what of the Kapa Haka? Fortunately, I can step back and listen to what Te Rita has to say about it directly, and so will limit myself to some wider structural observations.

I have written a great deal about the semiotics of the proscenium arch in relation to Kapa Haka on the Te Matatini Festival stage, arguing that the façade represents the legacy of colonisation in ways that should inform our understanding of the performance (see, for example, Mazer 2011). When Kapa Haka comes indoors in full force as it did on the St James stage - or on the Isaac Theatre Royal stage in Christchurch, where Te Rita and I saw it - the impact is extraordinary. These theatres represent the height of the settlers' aspirations, their manifest desire to remain civilised while planting themselves in the wilderness of the new world. (I feel like I should be putting inverted commas around most of these words.) The Kapa Haka performance we saw as the first part of Ihi FrENZy - the Ihi - was fully contained in this box, and from where I sat, whatever the contents of the song and dance, the point of the performance became this act of containment.

Ihi FrENZy was indeed a performance of two halves, but the halves were anything but equal, and they were kept at a great distance from one another - except for the valedictory 
ending, which magically closed the gap, and left us with a biculturalist vision that was, at least momentarily, not so bifurcated.

About the Kapa Haka. Allow me to be really blunt, to play the spectator who saw only what she saw on the night (with memory refreshed by modern technology), for the sake of provocation.

The Kapa Haka company looked massive: both in the scale of the native bodies next to the ballet bodies, and in sheer numbers. Their bodies were exposed and painted - classic native bodies, dressed by nature itself, it seemed. They produced their own sounds, much of it unintelligible: shrieks, cries, shouts, stomps, the slapping of poi against palms, a bit of guitar and te reo in chants and the occasional song (mostly in non-European harmonics). Their story was largely unintelligible and inaccessible to those not fluent in te reo and tikanga, but looked to be filled with superstition and, oh you know, all that native stuff. They were all gravity, with a kind of continuous relationship to the ground beneath their feet, even when stomping and leaping. They rushed hither and thither sometimes as if preparing for war and challenging the audience, at other times pulling themselves into line for a dance, of sorts - as if moved by instinct rather than by craft, convention, choreography. Not quite in unison, but not individuated either, for the most part, except for some moments of pure song leading to the culminating, ennobling moment, when savagery melted away, and the feather - the taonga - was left to be taken up by the Ballet. 


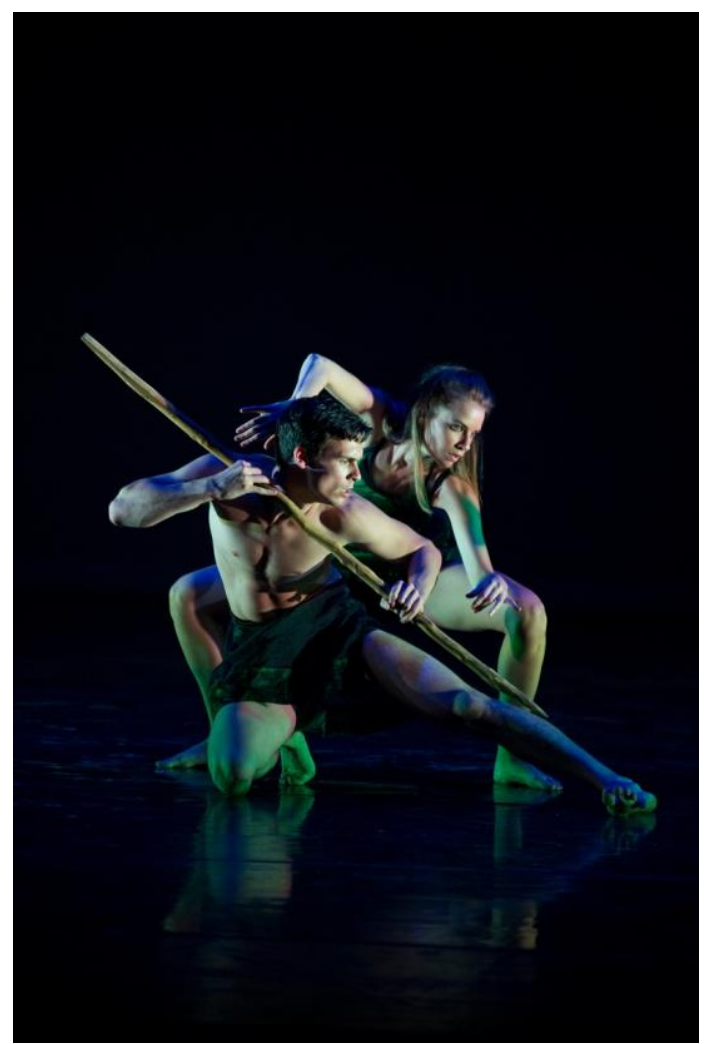

Photo: Stephen A'Court - Rangimarie by Merenia Gray Pictured: Olivia McGregor and Levi Cameron

For me, this production told an important truth, or two, about bicultural Aotearoa New Zealand. It just wasn't the truth the producers intended. The full meaning of the performance was in its asymmetries, its production of 'traditional' versus 'contemporary' and above all, its use of the native in performance to create an idea(1) of the Kiwi - the new New Zealander. We saw, in the most literal way possible, the binaries of the native versus the European not only 
reproduced but amplified. Whatever the Kapa Haka was, it was not contemporary, it was not Art.

As I said at the outset - easy target. There are, of course, a number of dance companies - not the NZ Ballet - who more successfully integrate 'traditional' Māori performance practices into their 'contemporary' dance performances. My favourite is Atamira Dance Collective, whose Ngai Tahu 32 had its genesis at Field Station, New Zealand: Environment/Performance, the Performance Studies international conference hosted by my department (Theatre and Film Studies, University of Canterbury) at Rēhua Marae in 2003 (see Mazer 2007). As I have observed elsewhere, in this performance and others like it, the binaries - the clichés of the 'native' and the 'European' also hold astonishingly firm, but at its best, here the socioaesthetic asymmetries can be seen to work in the reverse. The stage is altered to reflect the structure of a wharenui. Māori protocol frames the performance, and the flow of the European dance is interlaced, interrupted and re-formed by the interventions of haka, waiata-ā-ringa and so on. As a result, the passages of contemporary dance literally seem to pale in contrast to the Kapa Haka inflected passages, to give way and be subsumed in ways that are, dare I say, utopian . . . or at least hopeful?

Here, the Atamira dancers create what might be seen as 'contemporary indigenous dance' and, in so doing, they make Art. Their performances are framed by Māori protocol. Their dances are on themes of identity and culture that are close to their own beings as young Māori artists, telling stories of themselves in relation to their tippuna and exploring questions of how being Māori influence their lives here and now. They not only incorporate bits and pieces of Māori protocol and Kapa Haka; they elaborate on those forms using idioms from contemporary European dance, synthesise and hybridise the movements, so that as a result we see them developing a new dance vocabulary - one that is, in the end, perhaps, neither fully Māori nor completely European. It's also not necessarily 
satisfying when one watches from one side or the other of the cultural divide, but it can be seen as a start towards something new.

\section{Te Rita speaks}

Contemporary indigenous performance - is it Art? Kapa Haka might struggle to be called traditional, let alone contemporary, but for me it is absolutely Art. I wonder if perhaps Sharon has gone too far in implying that there is a dominant view in which dance performed by indigenous peoples cannot be seen as Art. But more on that later.

Let me start with my own response to Ihi FrENZy. Sharon and I actually saw this performance together in Christchurch. We also sat together when Atamira performed Ngai Tahu 32 in Christchurch. Both performances provoked us to talk at length about what happens to Kapa Haka when it's integrated into European dance contexts, and what such performances might mean for Māori identity and culture. It's great to have an opportunity to revisit those conversations here now.

Knowing Wetini well, and having seen him develop in the Māori Performing Arts to the stage that his kete mātauranga of haka was full enough for him to form his own kapa, I understood his trying to connect the old world of performance (Māori) to the new world of performance (ballet). As Sharon has mentioned, this in itself is a faulty ambition, as in fact ballet may be a new arena for combining Māori performance, but ballet itself is an old performance genre. Unlike Kapa Haka, which has evolved from early Māori Art and continues to represent itself with that origin firmly in place, ballet has a growth story that covers continents.

Like Kapa Haka, ballet developed from courtly rituals and entertainments, keeping time with social change as it grew into the theatrical art form we see now. Like Kapa Haka, ballet has a reputation for being frozen in some artificial past. 
In fact, we can see in Ihi FrENZy the steps taken by the New Zealand Ballet, dancing to the music of Split Enz, to break free of some of those conventional expectations. What bewilders me still is how much Wetini seems to have struggled with the challenge of theatricalising Kapa Haka for his portion of the performance - even to find a consistent theme and to maintain the corresponding repertoire. Kapa Haka is already theatrical. Had he forgotten? Or was it perhaps the proximity to the ballet and a misconception that the stage of the St James - or the Isaac Theatre Royal - demanded something beyond the normal reach of the art form of which he is a clear master?

You probably missed it, but there .. . I have used Kapa Haka and Art in the same sentence, being somewhat simplistic in describing Art as something that is entertaining, topical, crosses time and space, and is meaningful for performers and audiences in ways that matter. Kapa Haka is all this and more. I am actually quite comfortable in saying that Kapa Haka is an indigenous dance form, in part, and that it can also be labelled contemporary Art. I say 'in part' because Te Mātārae I O Rehu Kapa Haka - as opposed to the NZ Ballet and to Atamira - depends on te reo. And more deeply, on tikanga and kawa that are Māori. Having introduced te reo, of course, I have to acknowledge that language is also present in Ihi FrENZy, because the dancers dance to the words sung by Split Enz, and the Atamira Dance Collective uses waiata and karanga to accompany its dance movements.

The difference is that in the performances by the Ballet and by Atamira, the dancers have no voices. Does this matter? Does the Kapa Haka lose currency, its status potentially as a contemporary dance form, simply because the dancers generate their own music? Does the use of the voice in dance somehow bring native dancers down to earth in a way that takes them away from high Art and makes it seem something else, something primitive, in contrast to the European? 
I hear Sharon saying that the claim of 'indigenous' points in one direction - toward the 'traditional', that while indigenous dance might have an aesthetics it is not performed for aesthetic reasons per se. And she says that the 'contemporary' pulls in the opposite direction, towards the European, as a matter of course. In so doing, she repeats longstanding prejudices - intentionally I assume - about the civilised European in contrast to the primitive, the native. But she also reminds us that 'contemporary' in this context is not just a chronological marker for something going on in the $21^{\text {st }}$ century, but also a formal designation for the evolution of an art form and its presumed origins in the homelands of those who came from Europe, settled and cultivated this land.

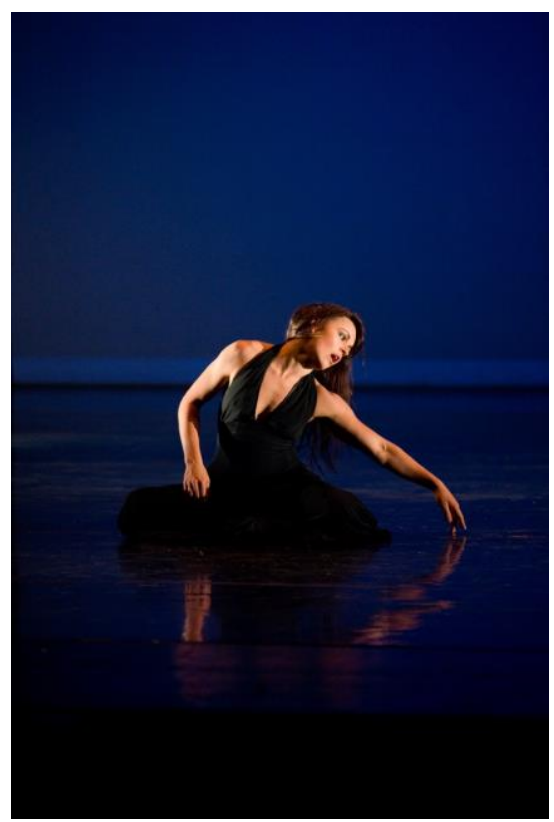

Photo: Stephen A'Court - Rangimarie by Merenia Gray Pictured: Emily Adams 
Wetini muddies the water a bit, because he identifies Kapa Haka with the old world and Ballet with the new, when it's really the other way around. While it looks to the past, and works to preserve our reo, tikanga, and kawa, Kapa Haka faces the present and speaks to the future of my people. It does so by weaving diverse performance practices with current themes and ideas, into patterns of movement and song that are at once formally conventionalised and constantly seeking something new. At its best, Kapa Haka holds the ground for us while also pushing the boundaries of what is performatively and socially possible.

Just as Art Historians have come to see tukutuku panels as both cultural (in the native sense) and Art (in the formal sense), so too Kapa Haka is simultaneously traditional and contemporary. Once we've come this far in the discussion, it seems obvious to suggest that so too we can say that ballet is at once traditional with at least the potential to be contemporary, and the same goes for the work done by Atamira and all the others. And we can use equivalent terms to analyse all three genres of performance for the way they speak, or not, to their audiences in the here and now.

How could it be otherwise? Dance (with or without song) is always cultural, constructed from and following the conventions of the peoples performing - traditional. The best dance, performed here and now, insofar as it both continues to develop in new ways and meets the present demands of its social context, can be called also contemporary and Art.

The problem really is with the word 'indigenous' for the way it points to a particular group of people in contrast to people identified as 'non-indigenous'. The binary implied here constructs an idea of the indigenous that is at odds with contemporary experience. As a Māori performing artist and scholar I do not come out of the bush intact - untouched by colonisation and globalisation, or for that matter untrained in European song and dance, as well as academics - when I stand before you. While I understand myself to be indigenous 
- in the sense of my whakapapa and tūrangawaewae - I am concerned at the limits implied by this label, this cutting off of one peoples' expressive arts practices (even to valorise them) when really what we might put ourselves to is the task of analysing - critically - what is produced by artists and called 'Art' for the ways in which these artefacts follow in and/or break from their cultural traditions and for their proficiency (or not), for their skill in telling a meaningful story in ways that move their audiences. That is, for their integrity and their aesthetics in the $21^{\text {st }}$ century.

\section{REFERENCES}

Mazer, S. (2007). Atamira Dance Collective: dancing in the footsteps of the ancestors. In M. Maufort and D. O'Donnell (Eds.), Performing Aotearoa: New Zealand theatre and drama in an age of transition (pp 283-292). Brussels: P.I.E. Peter Lang S.A.

Mazer, S. (2011). Performing Māori: Kapa Haka on the stage and on the ground. Popular Entertainment Studies 2(1), 41-53. Retrieved November 4, 2013, from https://novaojs.newcastle.edu.au/ojs/index.php/pes/article/vie wFile $/ 44 / 30$.

Papesch, T. R. \& Mazer, S. (2001). Crossing the cultural divide. Footprints/Tapuwae...Return of the Native. Produced by Te Puna Toi, the Performance Research wing of Theatre and Film Studies at the University of Canterbury.

Papesch, T. R. \& Mazer, S. (2010). Māori performance/cultural performance: stages of pōwhiri. Ngā Kete a Rēhua: Inaugural Māori Research Symposium - Te Waipounamu (pp. 276-281). Christchurch, New Zealand: Aotahi School of Māori and Indigenous Studies, University of Canterbury. Published proceedings of 2008 event.

Royal New Zealand Ballet. (2001). Ihi FrENZy. Retrieved 4 November, 2013, from http://www.nzballet.org.nz/about/repertoire/ihifrenzy.

Williams, Brent. (2003). Ihi FrENZy: the making of a dance. Wellington: Learning Media. Videorecording. 